\title{
Valor nutritivo do resíduo do processamento do caroço de algodão suplementado com levedura e avaliado em bovinos ${ }^{1}$
}

\author{
Juliana Duarte Messana ${ }^{2}$, Telma Teresinha Berchielli ${ }^{2}$, Pedro Braga Arcuri ${ }^{3}$, Ricardo Andrade \\ Reis $^{2}$, Alexandre Vaz Pires ${ }^{4}$, Euclides Braga Malheiros ${ }^{2}$ \\ 1 Pesquisa financiada pela FAPESP. \\ 2 Departamento de Zootecnia, Faculdade de Ciências Agrárias e Veterinárias - UNESP/Campus Jaboticabal-SP. Via de Acesso Profo Paulo \\ Donato Castellane s/n. CEP: 14884-900. Jaboticabal, SP. \\ ${ }^{3}$ Embrapa Centro Nacional de Pesquisa de Gado de Leite. \\ ${ }^{4}$ Departamento de Zootecnia, Universidade de São Paulo, Escola Superior de Agricultura Luiz de Queiroz - ESALQ, Piracicaba, SP.
}

RESUMO - O objetivo neste trabalho foi avaliar o consumo, a digestibilidade total e parcial da matéria seca (MS) e dos nutrientes e os parâmetros ruminais de novilhos alimentados com rações à base de resíduo do processamento do caroço de algodão (RPCA) suplementado com levedura seca de cana-de-açúcar. Foram utilizados seis novilhos Nelore canulados no rúmen e duodeno, alimentados com rações compostas de 80\% RPCA e 20\% concentrado, composto de milho, ureia e levedura nos níveis de 0, 20 ou 40\%. O delineamento experimental adotado para análise do consumo e da digestibilidade foi em blocos casualisados e a análise dos parâmetros ruminais foi em parcela subdividida. Os consumos e a digestibilidade de nutrientes não foram influenciados pela suplementação com levedura, fato que pode estar relacionado ao alto valor da fração C do resíduo do processamento do RPCA (44,51\% MS) e à baixa fração proteica de lenta degradação da levedura, que impediu a sincronização energia/nitrogênio para maior degradação do resíduo. O pH do líquido ruminal decresceu linearmente nos animais mantidos com as dietas suplementadas com levedura. Em todas as dietas, o pH e a concentração de $\mathrm{N}-\mathrm{NH}_{3}$ foram adequados para o crescimento microbiano. As concentrações ruminais de acetato, propionato, butirato e ácidos graxos voláteis totais e a relação acetato:propionato não foram influenciadas pela suplementação com levedura. O resíduo do processamento do caroço de algodão é uma opção a ser utilizada no arraçoamento de bovinos.

Palavras-chave: consumo, digestibilidade, fermentação ruminal, resíduo agroindustrial

\section{Nutritive value of cottonseed processing residue supplemented with yeast assessed with cattle}

\begin{abstract}
The objective of this study was to evaluate the intake, total and partial dry matter (DM) digestibility and the nutrients and ruminal parameters of steer fed diet based on cottonseed processing residue (CSPR) supplemented with sugarcane dried yeast. Six steers, with rumen and duodenal cannulae were fed diets consisting of $80 \%$ CSPR and $20 \%$ concentrate, consisting of corn, urea and yeast at levels of 0,20 or $40 \%$. A randomized block design was used to analyze intake and digestibility and the ruminal parameters were analyzed in split plots. The DM, OM, EE, NDF and ADF intake and digestibility were not influenced by yeast supplementation, possibly because of the high value of the $C$ fraction of the CSPR (44.51\% DM) and the low protein fraction of slow degradation of yeast that prevented synchronization energy/ nitrogen for greater residue degradation. The ruminal liquid $\mathrm{pH}$ decreased linearly in the animals kept on yeast supplemented diets. In all treatments the $\mathrm{pH}$ and ammonia nitrogen concentration were adequate for microbial growth. The ruminal concentrations of acetate, propionate, butyrate, total fatty acid and the acetate: propionate ratio values were not influenced by yeast supplementation. Cottonseed processing residue can be used as ruminant feedstuff.
\end{abstract}

Key Words: agroindustrial residue, intake, digestibility, ruminal fermentation

\section{Introdução}

Nos últimos anos, a busca por maior produtividade e menor custo de produção tem sido constante nas atividades agropecuárias, de modo que a utilização dos recursos disponíveis e causadores de problemas ambientais tem sido objetivo em muitas pesquisas. O destino do algodão brasileiro é a indústria têxtil e alimentícia. Após a colheita e o processamento, obtêm-se alguns subprodutos, como o resíduo do processamento do caroço de algodão, que é resultante da extração de óleo e é composto por línter e casca do caroço do algodão. 
Esses resíduos são ricos em energia potencialmente disponível para os ruminantes, em decorrência dos seus altos teores de celulose, hemicelulose e lignina (Santos et al., 2004). A degradação biológica da celulose consiste na hidrólise enzimática catalisada por celulases, complexos enzimáticos produzidos por fungos e bactérias. Entre os microrganismos produtores de celulases, os fungos têm despertado maior interesse, pois suas enzimas são secretadas no meio de cultura, capacitando-os a aproveitar celulose distante de suas hifas, enquanto as bactérias precisam estar aderidas à fibra da celulose para sua utilização (Castro et al., 2003).

Com base nos relatos da literatura, espera-se uma alternativa para melhorar a disponibilidade dessa fibra para os ruminantes, como o uso de suplementos à base de leveduras, que podem conter leveduras vivas e ser fornecidos diariamente em pequenas quantidades, atuando como probióticos, ou podem conter uma mistura nãoidentificada de pequena quantidade de células vivas, um grande número de células mortas e, ainda, fragmentos de células e resíduos do metabolismo das mesmas leveduras, por exemplo, a levedura seca de cana-de-açúcar.

No rúmen, leveduras vivas parecem elevar o consumo, por aumentarem a taxa de degradação da fibra, causando aumento expressivo no número de bactérias anaeróbias e maior estabilidade do ambiente ruminal, reduzindo-se as variações diurnas de pH, amônia e ácidos graxos voláteis (Huber et al., 1994; Wallace, 1994). No caso de o suplemento de leveduras não ser um probiótico, acredita-se que o efeito do mesmo seja por meio do fornecimento de nutrientes prontamente disponíveis e de alto valor biológico, como proteína microbiana, vitaminas e açúcares (Blumer, 2002).

Desta forma, realizou-se este trabalho para avaliar o consumo de matéria seca (CMS) e nutrientes, a digestibilidade total e parcial e os parâmetros ruminais de rações à base de resíduo do processamento do caroço de algodão suplementado com levedura seca de cana-de-açúcar.

\section{Material e Métodos}

O experimento foi conduzido no Setor de Avaliação de Alimentos e Digestibilidade pertencente ao Departamento de Zootecnia da Faculdade de Ciências Agrárias e Veterinárias - UNESP, Campus de Jaboticabal, São Paulo. Foram utilizados seis novilhos da raça Nelore, castrados, canulados no rúmen e no duodeno, com peso médio inicial de $390 \mathrm{~kg}$ e aproximadamente 30 meses de idade. Durante o período de adaptação, os animais foram alojados em baias individuais com 3,00 × 7,20 m, com bebedouros comuns a duas baias, e posteriormente foram transferidos para gaiolas metabólicas no início de cada período de coleta dos dados.

As dietas fornecidas foram ajustadas de acordo com o CNCPS (Fox et al., 2003), para atender às exigências de crescimento microbiano e compostas de resíduo do processamento do caroço de algodão (RPCA) como volumoso (80\%) e concentrado (20\%), formulado com milho, ureia e levedura nos níveis de 0,20 ou $40 \%$ (Tabelas 1 e 2).

O período experimental teve duração de 88 dias e foi dividido em quatro períodos de 22 dias (15 de adaptação e 7 de coleta de dados). As amostragens dos alimentos foram realizadas diariamente, durante os sete dias de coleta,

Tabela 1 - Composição dos ingredientes das dietas experimentais

\begin{tabular}{|c|c|c|c|c|}
\hline & \multicolumn{4}{|c|}{ Alimento } \\
\hline & Resíduo $^{1}$ & Milho & Levedura & Ureia \\
\hline \multicolumn{5}{|l|}{ Nutriente } \\
\hline Matéria seca (\%MN) & 90,77 & 86,32 & 93,81 & 98,00 \\
\hline Proteína bruta (\% MS) & 13,88 & 10,74 & 47,03 & 275,00 \\
\hline Matéria orgânica (\% MS) & 96,76 & 98,59 & 96,62 & - \\
\hline Extrato etéreo (\% MS) & 8,83 & 5,26 & 0,09 & - \\
\hline Matéria mineral (\% MS) & 3,24 & 1,41 & 3,38 & - \\
\hline Lignina (\% MS) & 18,54 & 2,45 & - & - \\
\hline $\begin{array}{l}\text { Fibra em detergente } \\
\text { neutro (\% MS) }\end{array}$ & 66,47 & 14,01 & - & - \\
\hline $\begin{array}{l}\text { Fibra em detergente } \\
\text { ácido (\% MS) }\end{array}$ & 60,98 & 2,87 & - & - \\
\hline Energia bruta (Mcal/kg) & 4,86 & 4,16 & 4,33 & - \\
\hline Fração A (\% PB) & 16,25 & 2,04 & 14,25 & - \\
\hline Fração B1 (\% PB) & 4,03 & 1,88 & 5,69 & - \\
\hline Fração B2 (\% PB) & 25,19 & 46,1 & 80,1 & - \\
\hline Fração B3 (\% PB) & 22,47 & 48,32 & 0,00 & - \\
\hline Fração C (\% PB) & 32,06 & 1,66 & 0,00 & - \\
\hline $\begin{array}{l}\text { Carboidratos totais } \\
\text { (\% MS) }\end{array}$ & 74,05 & 82,59 & 49,49 & - \\
\hline $\begin{array}{l}\text { Carboidratos não-fibrosos } \\
\text { (\% MS) }\end{array}$ & 8,12 & 68,74 & 49,49 & - \\
\hline Fração B2 (\% MS) & 21,42 & 7,95 & 0,00 & - \\
\hline Fração C (\% MS) & 44,51 & 05,90 & 0,00 & - \\
\hline
\end{tabular}

${ }^{1}$ Resíduo do processamento do caroço de algodão.

Tabela 2 - Porcentagem dos ingredientes e composição química das dietas experimentais

\begin{tabular}{lccc}
\hline & \multicolumn{3}{c}{ Nível de levedura } \\
& (\% no concentrado) \\
\cline { 2 - 4 } Ingrediente (\%) & 0 & 20 & 40 \\
\hline Resíduo do caroço de algodão & 80,0 & 80,0 & 80,0 \\
Levedura seca & 0,0 & 4,0 & 8,0 \\
Milho moído & 18,6 & 14,9 & 11,3 \\
Ureia & 1,4 & 1,0 & 0,7 \\
Nutriente (\%) & & & \\
Matéria seca (\%) & & & \\
Matéria orgânica (\%MS) & 90,0 & 90,3 & 90,5 \\
Proteína bruta (\%MS) & 95,8 & 96,0 & 96,3 \\
Extrato etéreo (\%MS) & 16,9 & 17,5 & 18,0 \\
Fibra em detergente neutro (\%MS) & 5,0 & 7,8 & 7,7 \\
Fibra em detergente ácido (\%MS) & 49,3 & 55,3 & 54,7 \\
Lignina (\%MS) & 15,3 & 15,2 & 15,1 \\
\hline
\end{tabular}


para determinação da composição e fracionamento dos ingredientes da dieta experimental.

As rações foram fornecidas uma vez ao dia, pela manhã, e as sobras foram retiradas e pesadas diariamente, antes da alimentação, para cálculo do consumo de matéria seca.

Para determinar a digestibilidade aparente no trato digestivo total, foi utilizada a coleta total de fezes. As fezes foram retiradas diariamente das bandejas às 7 horas, pesadas, homogeneizadas e amostradas separadamente por animal, em quantidade de aproximadamente 500 g. A coleta e pesagem das fezes foram iniciadas 24 horas após o fornecimento da dieta para os animais. Para determinação da digestibilidade parcial, foram coletadas amostras de digesta duodenal (Oliveira, 2007).

As amostras de líquido ruminal foram coletadas manualmente, filtradas em tecido duplo de algodão, a fim de se obterem $100 \mathrm{~mL}$ de líquido ruminal, e posteriormente devolvidas para dentro do rúmen. As coletas foram realizadas antes do fornecimento da dieta e 2, 4, 8 e 12 horas após a alimentação, para a determinação do $\mathrm{pH}$, das concentrações de nitrogênio amoniacal $\left(\mathrm{N}-\mathrm{NH}_{3}\right)$ e dos ácidos graxos voláteis (AGV).

A fermentação ruminal foi mensurada pela análise de $\mathrm{pH}$, concentração de $\mathrm{N}-\mathrm{NH}_{3}$ e AGV . A determinação do pH do líquido ruminal foi feita logo após a coleta, em peagômetro digital. Uma alíquota de $2 \mathrm{~mL}$ do fluido coletado foi adicionada em frasco de plástico e congelada a $-20^{\circ} \mathrm{C}$, para posterior análise de ácidos graxos voláteis, segundo método adaptado de Erwin et al. (1961), utilizando-se cromatografia gasosa.

Uma alíquota de $40 \mathrm{~mL}$ de fluido ruminal foi levada para o laboratório para análise do nitrogênio amoniacal, realizada por destilação com hidróxido de potássio $2 \mathrm{~N}$, conforme metodologia adaptada por Vieira (1980).

As amostras dos alimentos, das sobras, da digesta duodenal e das fezes foram analisadas quanto aos teores de matéria seca (MS), matéria mineral (MM), energia bruta (EB), extrato etéreo (EE) e proteína bruta (PB), de acordo com AOAC (1990), descrito por Silva \& Queiroz (2002).

A fibra em detergente ácido (FDA) e a fibra em detergente neutro (FDN) foram analisadas de acordo com método de Van Soest \& Robertson (1985). O fracionamento dos compostos nitrogenados foi realizado de acordo com o protocolo descrito por Krishnamoorthy et al. (1982) e as frações dos carboidratos foram obtidas utilizando-se a metodologia descrita por Sniffen et al. (1992).

Os coeficientes de digestibilidade total e ruminal foram obtidos com base na diferença da quantidade de alimento ingerido, na produção fecal e no fluxo de MS digesta duodenal, respectivamente. O coeficiente de digestão da matéria seca foi determinado de acordo com a equação: $\mathrm{MS}=$ $100 \times$ [MS ingerida-MS fecal ou MS duodenal / MS ingerida].

Para determinação dos fluxos diários de MS no duodeno, utilizou-se como indicador interno a fibra em detergente neutro indigestível (FDNi), obtida pela metodologia in situ, após 144 horas de incubação (Berchielli et al., 2000). Para cálculo de fluxo de MS duodenal foi utilizada a equação: Fluxo de MS duodenal = $((\mathrm{MS}$ fecal $\times \%$ FDN na MS fecal)/\% FDN indigestível na MS duodenal).

O delineamento experimental utilizado para avaliar consumo e coeficiente de digestibilidade foi o de blocos casualisados, composto de quatro períodos, seis animais e três tratamentos. As análises estatísticas dos parâmetros ruminais ( $\mathrm{pH}$, nitrogênio amoniacal e ácidos graxos voláteis) foram realizadas em esquema de parcelas subdivididas, tendo na parcela os tratamentos e nas subparcelas o tempo de coleta. As análises de variância foram realizadas utilizando-se o procedimento GLM do programa SAS (1991). Para comparação das médias foi utilizado teste Tukey a 5\% de probabilidade.

\section{Resultados e Discussão}

O fornecimento de nutrientes e energia em teores adequados ao atendimento das exigências dos animais, assim como o estabelecimento de condições que melhorem o consumo de matéria seca, é fundamental para que o alto desempenho produtivo dos animais seja alcançado. O consumo observado (Tabela 3 ) evidencia que a suplementação com levedura seca de cana-de-açúcar não teve efeito significativo sobre o desempenho dos animais. Entretanto, o consumo observado pode ser considerado razoável em se tratando de resíduos com FDN de baixa qualidade, como o resíduo do processamento do caroço de algodão.

A composição do resíduo do processamento do caroço de algodão não é homogênea e varia conforme a origem e forma de processamento (Tabela 1); apesar disso, não interferiu no consumo. Melhores resultados de consumo foram observados por Duarte et al. (2006), que estudaram o resíduo da indústria têxtil de algodão e obtiveram ingestão de matéria seca igual a $6,54 \mathrm{~kg} /$ dia quando substituíram a cana em $75 \%$ por esse subproduto.

De acordo com Mertens (1994), o consumo de matéria seca responde por 60 a $90 \%$ das respostas no desempenho animal, e 10 a $40 \%$ desse consumo depende das variações na digestibilidade. As características físicas e químicas da ração e, principalmente as interações entre esses fatores, possuem efeito predominante sobre o consumo de matéria seca. 
Tabela 3 - Consumo de matéria seca e nutrientes em bovinos alimentados com dietas com resíduo do processamento do caroço de algodão e levedura seca

\begin{tabular}{|c|c|c|c|c|c|}
\hline \multirow[t]{2}{*}{ Item } & \multicolumn{3}{|c|}{ Nível de levedura (\% no concentrado) } & \multirow[b]{2}{*}{ Médias } & \multirow[b]{2}{*}{$\mathrm{CV}$} \\
\hline & 0 & 20 & 40 & & \\
\hline Matéria seca (kg/dia) & 7,4 & 7,6 & 7,3 & 7,4 & 11,4 \\
\hline Matéria orgânica (kg/dia) & 7,1 & 7,2 & 7,0 & 7,1 & 11,6 \\
\hline Proteína bruta (kg/dia) & 1,2 & 1,3 & 1,3 & 1,3 & 11,6 \\
\hline Extrato etéreo (kg/dia) & 0,6 & 0,6 & 0,6 & 0,6 & 11,0 \\
\hline Energia (Mcal/kg) & 342,3 & 347,1 & 347,5 & 345,6 & 11,9 \\
\hline Fibra em detergente ácido (kg/dia) & 3,6 & 3,7 & 3,5 & 3,6 & 11,3 \\
\hline
\end{tabular}

Médias seguidas de letras diferentes nas linhas diferem entre si pelo teste de Tukey $(\mathrm{P}<0,05)$.

$\mathrm{CV}=$ coeficiente de variação.

A quantidade de FDA digerida no rúmen foi em média $3,8 \%$ superior à digerida no trato gastrintestinal total (Tabela 4). No rúmen, também foi observado aumento de 2,1\% nas digestibilidades da MO, 4\% do EE, 6\% da EB e 2,4\% da FDA, em comparação aos observados nos animais alimentados com as dietas sem levedura e com $40 \%$ de levedura. De acordo com Williams et al. (1991), esse efeito poderia ser explicado pelo aumento da taxa inicial de digestão da celulose (menor tempo de colonização), sem aumento na extensão dessa taxa, relatado por Callaway \& Martin (1997).

O resíduo de processamento do caroço de algodão apresenta proteína bruta em concentração potencialmente suficiente para garantir a atividade microbiana (13,8\% MS), porém, a fração C é alta (32,0\%) e a fração de carboidratos também é elevada (44,5\%MS), o que resulta em baixa digestibilidade da fibra. Portanto, a fibra desse subproduto apresenta menor taxa de degradação efetiva no rúmen (Banys et al., 1999), causando redução na taxa de passagem.
Os teores de FDN do resíduo do processamento do caroço de algodão (Tabela 2) são elevados e os de lignina também, fato que determina a lenta velocidade de degradação pela microbiota e, concomitantemente, ausência de sincronismo entre a disponibilidade de energia e a de nitrogênio, um fator que atua no valor nutritivo desse resíduo.

A dieta sem levedura, com maior proporção de milho moído (Tabela 1) apresentou maior digestibilidade da energia em comparação àquela com $20 \%$ de levedura, o que pode ter sido ocasionado pelo fornecimento de maior quantidade de carboidratos de rápida degradação para os microrganismos do rúmen. Além disso, a energia do resíduo do processamento do caroço de algodão não está prontamente disponível para ser aproveitada no rúmen, por causa da baixa qualidade de sua porção fibrosa e da pequena proporção de carboidratos de fácil degradação.

Cecava et al. (1991) sugeriram que dietas com concentrados à base de milho aumentam a disponibilidade de

Tabela 4 - Digestibilidade aparente total e ruminal dos nutrientes em novilhos alimentados com rações contendo resíduo do processamento do caroço de algodão e levedura seca

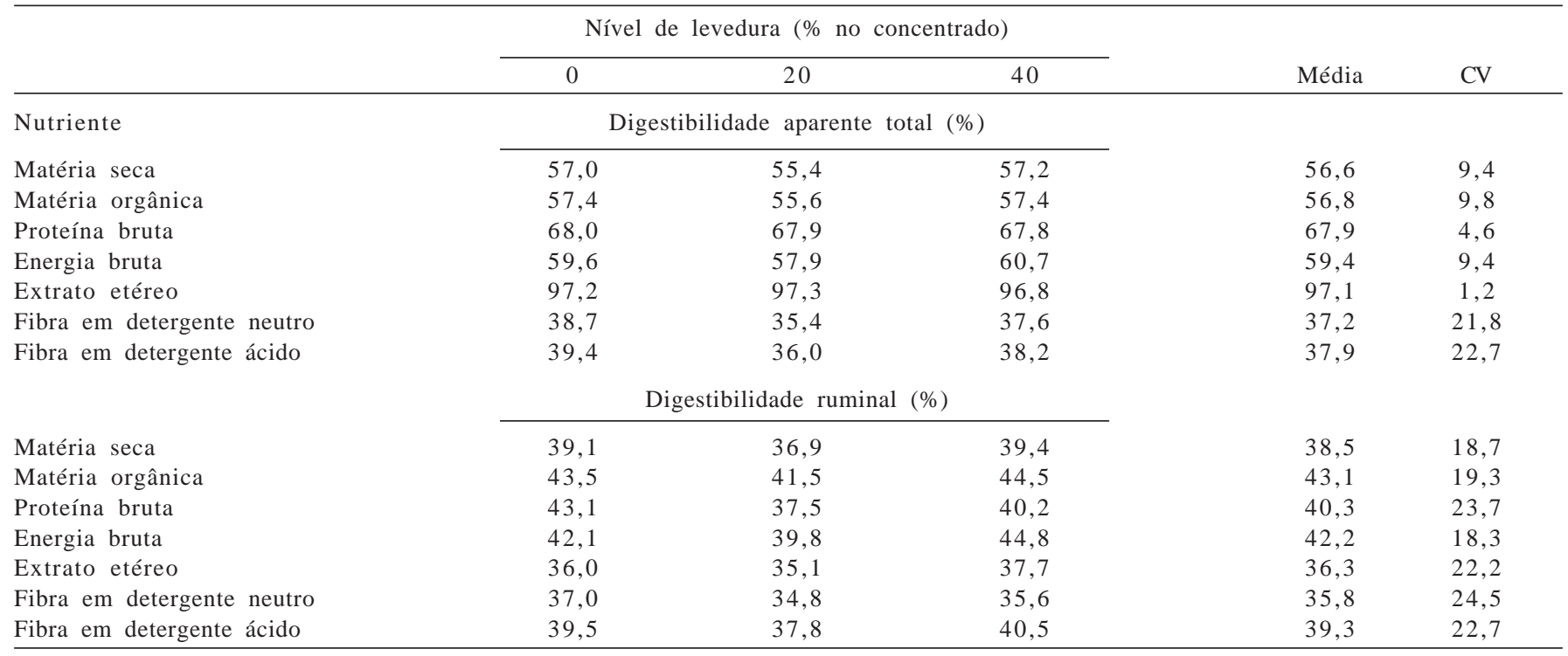

Médias seguidas de letras iguais nas linhas não diferem entre si $(\mathrm{P}>0,05)$ pelo teste de Tukey.

$\mathrm{CV}=$ coeficiente de variação. 
energia em todo trato gastrintestinal, provavelmente em virtude das fontes mais digestíveis de carboidratos, como o amido. Outro fator que estaria relacionado à baixa digestibilidade do resíduo do processamento do caroço de algodão é o composto antinutricional, o gossipol, que, dependendo da forma em que se encontra (forma livre ou complexada com proteína) e da sua concentração nos produtos originados do algodão (Noftsger et al., 2000), pode atuar na microbiota e causar a intoxicação. Mena et al. (2001) propuseram que a detoxificação no rúmen reduz quando a taxa de passagem ruminal de alimentos que contêm gossipol é aumentada.

Os valores médios de $\mathrm{pH}$ (Tabela 5) não diferiram significativamente entre as dietas, tendo em vista a relação volumoso:concentrado, igual entre as dietas, e o poder de osmorregulação ruminal. Os valores médios de $\mathrm{pH}$ ruminal (Figura 1) foram semelhantes ( $\mathrm{P}>0,05)$ nos horários de 0 e 2 horas ( 7,1 e 7,0 , respectivamente) e apresentaram diferença nas avaliações às 4,8 e 12 horas $(6,9 ; 6,6$ e 6,5, respectivamente) após a alimentação, em todas as dietas. Os valores de $\mathrm{pH}$ variaram em resposta aos tempos de amostragem $(\mathrm{P}<0,05)$, o que indica variabilidade do $\mathrm{pH}$ do conteúdo ruminal em decorrência do arraçoamento. No período de 12 horas, entretanto, esse efeito não foi observado nos valores de $\mathrm{pH}$ do líquido ruminal $(\mathrm{P}>0,05)$.

Os maiores valores de $\mathrm{pH}$ foram encontrados 2 horas após a alimentação em todas as dietas, mas diminuíram após esse horário, provavelmente em decorrência da preponderância de celulose e outros carboidratos que são metabolizados lentamente (Hungate, 1966). Os valores de $\mathrm{pH}$ ruminal observados neste experimento estão na faixa de 7,11 a 6,48, na qual o processo de degradação da fibra ocorre de forma adequada (Allen \& Mertens, 1988).

As concentrações máximas de $\mathrm{N}-\mathrm{NH}_{3}$ ruminal foram de 16,$0 ; 19,6$ e $17,2 \mathrm{mg} \mathrm{N}-\mathrm{NH}_{3} / 100 \mathrm{~mL}$ de líquido ruminal nos animais alimentados com as rações sem levedura e com $20 \%$ e $40 \%$ de levedura no concentrado, respectivamente (Figura 1).

Tabela 5 - Parâmetros ruminais de bovinos alimentados RPCA com diferentes teores de levedura

\begin{tabular}{lcccc}
\hline Parâmetro ruminal & \multicolumn{3}{c}{$\begin{array}{c}\text { Nível de levedura } \\
\text { (\% no concentrado) }\end{array}$} & \\
\cline { 2 - 4 } & 0 & 20 & 40 & CV (\%) \\
\cline { 2 - 4 } & 6,8 & 6,8 & 6,8 & 4,5 \\
$\mathrm{pH}$ & 11,5 & 12,5 & 12,1 & 59,0 \\
$\mathrm{~N}-\mathrm{NH}_{3}$ (mg/dL) & 88,4 & 87,2 & 89,1 & 21,7 \\
$\begin{array}{l}\text { Ácidos graxos voláteis } \\
\text { Ácidos graxos voláteis }\end{array}$ & & & & \\
totais & 53,2 & 54,3 & 54,7 & 18,2 \\
$\begin{array}{l}\text { Acético } \\
\text { Propiônico }\end{array}$ & 28,1 & 27,9 & 28,1 & 37,0 \\
Butírico & 6,0 & 6,0 & 6,3 & 33,5 \\
Relação & 2,1 & 2,0 & 2,1 & 21,3
\end{tabular}

acético:propiônico

$\mathrm{N}-\mathrm{NH}_{3}=$ nitrogênio na forma de amônia.

Médias seguidas de letras iguais nas linhas não diferem entre si $(\mathrm{P}>0,05)$ pelo teste de Tukey.

$\mathrm{CV}=$ coeficiente de variação.
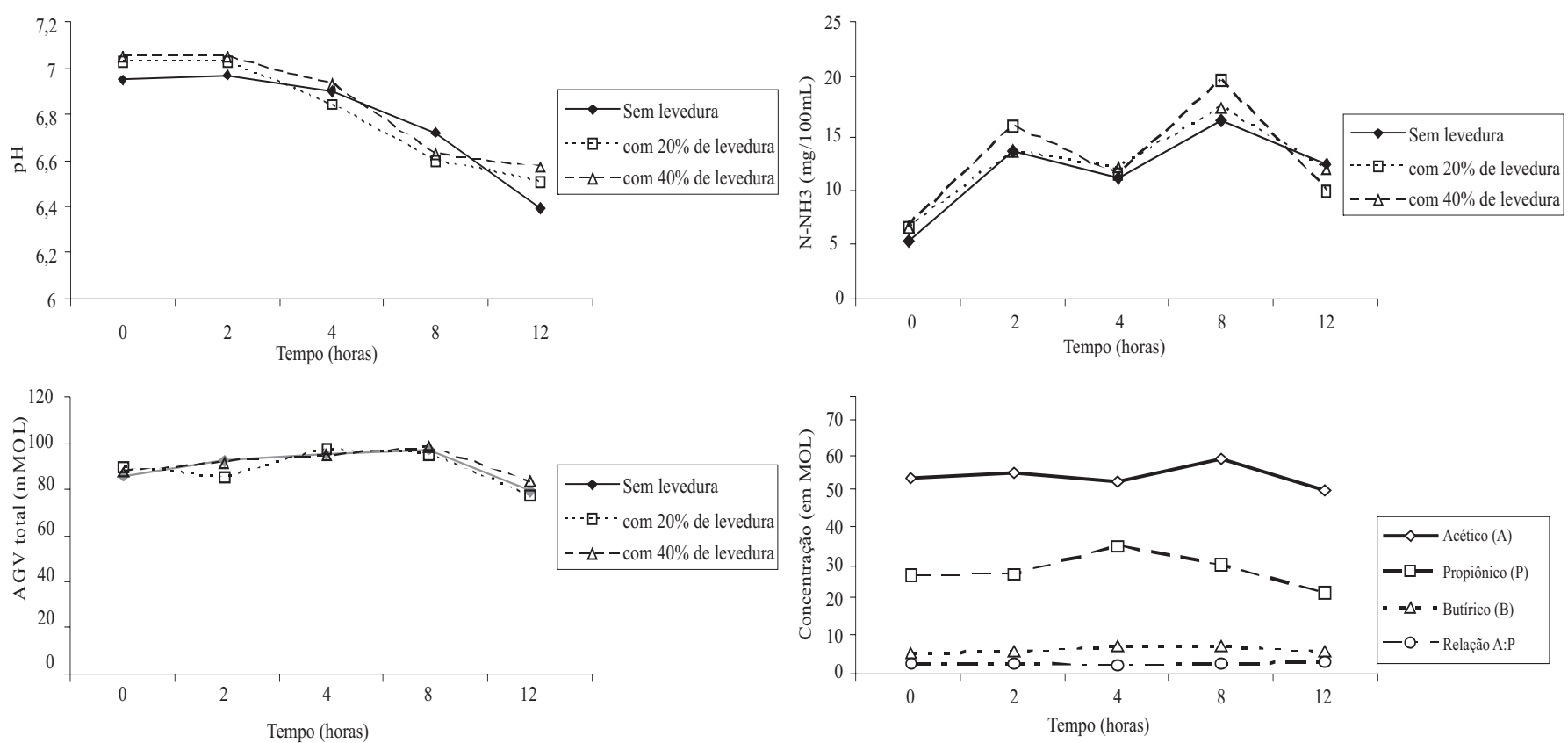

Figura 1 - Valores médios de pH ruminal, nitrogênio amoniacal ruminal e concentração de ácidos graxos antes (0), 2, 4, 8 e 12 horas após alimentação dos animais com resíduo do processamento do caroço de algodão. 
As concentrações de $\mathrm{N}-\mathrm{NH}_{3}$ ruminal foram suficientes para suportar o crescimento bacteriano, de acordo com o valor mínimo ideal citado por Satter \& Slyter (1974) de 5 mg $\mathrm{N}-\mathrm{NH}_{3} / 100 \mathrm{~mL}$. De acordo com Van Soest (1994), teores de $\mathrm{N}-\mathrm{NH}_{3}$ inferiores a $13 \mathrm{mg} / 100 \mathrm{~mL}$ no rúmen podem afetar a disponibilidade de nitrogênio para os microrganismos, comprometendo a ingestão e digestibilidade da fibra. Os valores observados nesta pesquisa estão dentro da faixa descrita como ideal por esses autores. Pelos coeficientes obtidos, no entanto, não houve efeito dos teores de nitrogênio amoniacal e da digestibilidade ruminal da fibra.

A concentração $\mathrm{N}-\mathrm{NH}_{3}$ ruminal é consequência do equilíbrio entre sua produção, absorção e utilização pelos microrganismos, a qual depende da quantidade de energia disponível.

Os dois picos de produção de nitrogênio amoniacal (Figura 1) estão relacionados à diferença de degradação entre as fontes proteicas utilizadas, uma vez que o resíduo do processamento do caroço de algodão (RPCA) apresentou em sua composição elevadas quantidades de compostos nitrogenados da fração $B_{3}$ e $B_{2}$ (Tabela 2), que são lentamente degradados, ou melhor, atinge sua maior produção de $\mathrm{N}-\mathrm{NH}_{3} 8$ horas após seu consumo pelo animal.

A concentração total de ácidos graxos voláteis não apresentou diferença estatística entre as três dietas (Tabela 5; Figura 1). A concentração de AGV total mostrou uma curva com diferentes picos entre as dietas, como consequência da fermentação de carboidratos solúveis e proteína de rápida degradação, como é o caso da levedura de cana-de-açúcar, que foi rapidamente degradada. Essa desuniformidade ocorreu por causa da ausência de sincronização entre a disponibilidade de energia e nitrogênio. $\mathrm{O}$ assincronismo entre a liberação de amônia e a energia disponível no rúmen resulta em ineficiente utilização de substratos fermentáveis (NRC, 2001).

A concentração de ácido butírico e propiônico aumentou logo nas primeiras 4 horas após a alimentação, resultado da fermentação de carboidratos solúveis e proteínas. Logo após esse período, há a estabilidade da concentração desses ácidos com queda 8 horas após a alimentação quando há um segundo pico de produção de ácido acético, em virtude da degradação da fibra da dieta. O resíduo do processamento do caroço de algodão tem fibra de degradação lenta (Tabela 2) e alto valor da fração $B_{2}$.

O pico de ácido acético 8 horas após a alimentação é devido também à degradação da proteína, fração $\mathrm{B}_{3}$ do RPCA, que é alta e lentamente degradável. Assim, seria necessária análise da degradabilidade desse resíduo. Para formulação de uma dieta ideal baseada no resíduo do processamento do caroço de algodão, seria essencial a utilização de fontes de nitrogênio de lenta degradação com vistas à adequada sincronização com a liberação da energia para otimizar a síntese de proteína microbiana.

\section{Conclusões}

O resíduo do processamento do caroço de algodão é uma opção a ser utilizada no arraçoamento de bovinos, mas é necessária a correção de suas deficiências nutricionais para utilização como alimento para ruminantes. A adição de levedura seca de cana-de-açúcar não altera o padrão de consumo da dieta, ainda que os níveis de consumo tenham sido satisfatórios para ganhos de peso economicamente viáveis em criatórios comerciais.

\section{Literatura Citada}

ALLEN, M.S.; MERTENS, D.R. Evaluating constraints on fiber ingestion by rumen microbes. Symposium: rumen productivity. Journal Nutrition, v.118, n.2, p.261-270, 1988.

ASSOCIATION OF OFFICIAL ANALYTICAL CHEMISTS AOAC. Official methods of analysis. 12.ed. Washington, D.C.: AOAC International, 1990. 1098p.

BANYS, V.L.; PAIVA, P.C.A.; REZENDE, C.A.P. et al. Composição bromatológica e degradabilidade de resíduo da indústria têxtil em bovinos. In: REUNIÃO ANUAL DA SOCIEDADE BRASILEIRA DE ZOOTECNIA, 35., 1999, Porto Alegre. Anais... Porto Alegre: Sociedade Brasileira de Zootecnia, 1999. (CD-ROM).

BERCHIELli, T.T.; ANDRADE, P.; FURLAN, C.L. Avaliação de indicadores internos em ensaios de digestibilidade. Revista Brasileira de Zootecnia, v.29, p.830-833, 2000.

BLUMER, S.A.G. Enriquecimento com ferro em levedura Saccharomyces cerevisae. 2002. 53f. Dissertação (Mestrado em Agronomia) - Escola Superior de Agricultura "Luiz de Queiroz”/Universidade de São Paulo, Piracicaba, 2002.

CALLAWAY, E.S.; MARTIN, S.A. Effects of a Saccharomyces cerevisae culture on ruminal bacteria that utilize lactate and digest cellulose. Journal of Dairy Science, v.80, p.2035-2044, 1997.

CASTRO, A.L.A.; PAIVA, P.C.A.; SOUZA DIAS, E. et al. Avaliação das alterações bromatológicas e de degradabilidade do resíduo de lixadeira do algodão após tratamento biológico com Pleurotus sojor-caju. Ciência e Agrotecnologia, v.28, n.3, p.613-618, 2004.

CECAVA, M.J.; MERCHEN, N.R.; BERGER, L.L. Effects of dietary energy level and protein source on nutrient digestion and ruminal nitrogen metabolism in steers. Journal of Animal Science, v.69, p.2230-2243, 1991.

DUARTE, J.; BERCHIELLI, T.T.; OLIVEIRA, S.G. et. al. Digestibilidade do resíduo do processamento do caroço de algodão em bovinos de corte. Ars Veterinária, v.22, p.56-62, 2006.

ERWIN, E.S.; MARCO, G.J.; EMERY, E.M. Volatile fatty acid analises of blood and rumen fluid by gas chromatography. Journal of Dairy Science, v.44, p.1768-1771, 1961.

FOX, D.G.; TYLUTKI, T.P.; TEDESCHI, L.O. et al. The net carbohydrate and protein system for evaluating herd nutrition and nutrient excretion. CNCPS version 5.0. New York, Ithaca: Cornell University, 2003. 237p.

HUBER, J.T.; HIGGINBOTHAM, G.; GOMEZ-ALRCON, R.A. et al. Heat stress interactions with protein, supplemental fat, and fungal cultures. Journal of Dairy Science, v.77, p.2080-2090, 1994. 
HUNGATE, R.E. The rumen and its Microbes. New York: Academic Press, 1966.

KRISHNAMOORTHY, U.; MUSCATO, T.V.; SNIFFEN, C.J. Nitrogen fraction in selected feedstuffs. Journal Dairy Science, v.65, p.217-225, 1982.

MENA, H.; SANTOS, J.E.P.; HUBER, J.T. The effects of feeding varying amounts of gossypol from whole cottonseed and cottonseed meal in lactating dairy cows. Journal of Dairy Science, v.84, p.2231-2239, 2001.

MERTENS, D.R. Regulation of forage intake. In: FAHEY JR., G.C. (Ed.) Forage quality, evaluation and utilization. Madison: American Society of Agronomy. 1994. p.450-493.

NATIONAL RESEARCH COUNCIL - NRC. Nutrient requirements of dairy cattle. 7.ed. Washington, D.C: National Academy Press, 2001. 381p.

NOFTSGER, S.M.; HOPKINS, B.A.; DIAZ, D.E. Effect of whole and expanded- expelled cottonseed on milk yield and blood gossypol. Journal of Dairy Science, v.83, p.2539-2547, 2000.

OLIVEIRA, S.G.; BERCHIELLI, T.T.; PEDREIRA, M.S. et al. Effect of tannin levels in sorghum silage and concentrate supplementation on apparent digestibility and methane emission in beef cattle. Animal Feed Science and Technology, v.135, p.236-248, 2007.

SANTOS, J.; CASTRO, A.L.A.; PAIVA, P.C.A. et al. Efeito dos tratamentos físicos e químicos no resíduo de lixadeira do algodão. Ciência Agrotecnica, v.28, p.919-923, 2004.
SATTER, L.D.; SLYTER, L.L. Effect of ammonia concentration on rumen microbial protein production in vitro. British Journal Nutrition, v.32, p.199-208, 1974.

SILVA, D.J.; QUEIROZ, A.C. Análise de alimentos. Métodos químicos e biológicos. 3.ed. Viçosa, MG: Editora da UFV, 2002.

SNIFFEN, C.J.; O’CONNOR, J.D.; VAN SOEST, P.J. et al. A net carbohydrate and protein system for evaluation cattle diets. 2 . Carbohydrate and protein availability. Journal of Animal Science, v.70, p.3562-3577, 1992.

STATISTICAL ANALYSIS SYSTEM - SAS. SAS/STAT ${ }^{\circledR}$ User's guide: statistics. Cary: 1991. 965p.

VAN SOEST, P.J. Nutritional ecology of the ruminant. Ithaca: Cornell University Press, 1994. 476p.

VAN SOEST, P.J.; ROBERTSON, J.B. Analysis of forages and fibrous foods. 1.ed. Ithaca: Cornell University, 1985. 202p.

VIEIRA, P.F. Efeito do formaldeído na proteção de proteína e lipídeos em ração para ruminantes. 1980. 98f. Tese (Doutorado em Zootecnia) - Universidade Federal de Viçosa, Viçosa, MG, 1980.

WALLACE, R.J. Ruminal microbiology, biotechnology, and ruminant nutrition: progress and problems. Journal of Animal Science, v.72, p.2992-3003, 1994.

WILLIAMS, P.E.V.; TAIT, C.A.G.; INNES, G.M. et al. Effects of the inclusion of yeast culture (Saccharomyces cerevisae plus growth medium) in the diet of dairy cows on milk yield and forage degradation and fermentation patterns in the rumen of steers. Journal of Animal Science, v.69, p.3016-3026, 1991. 